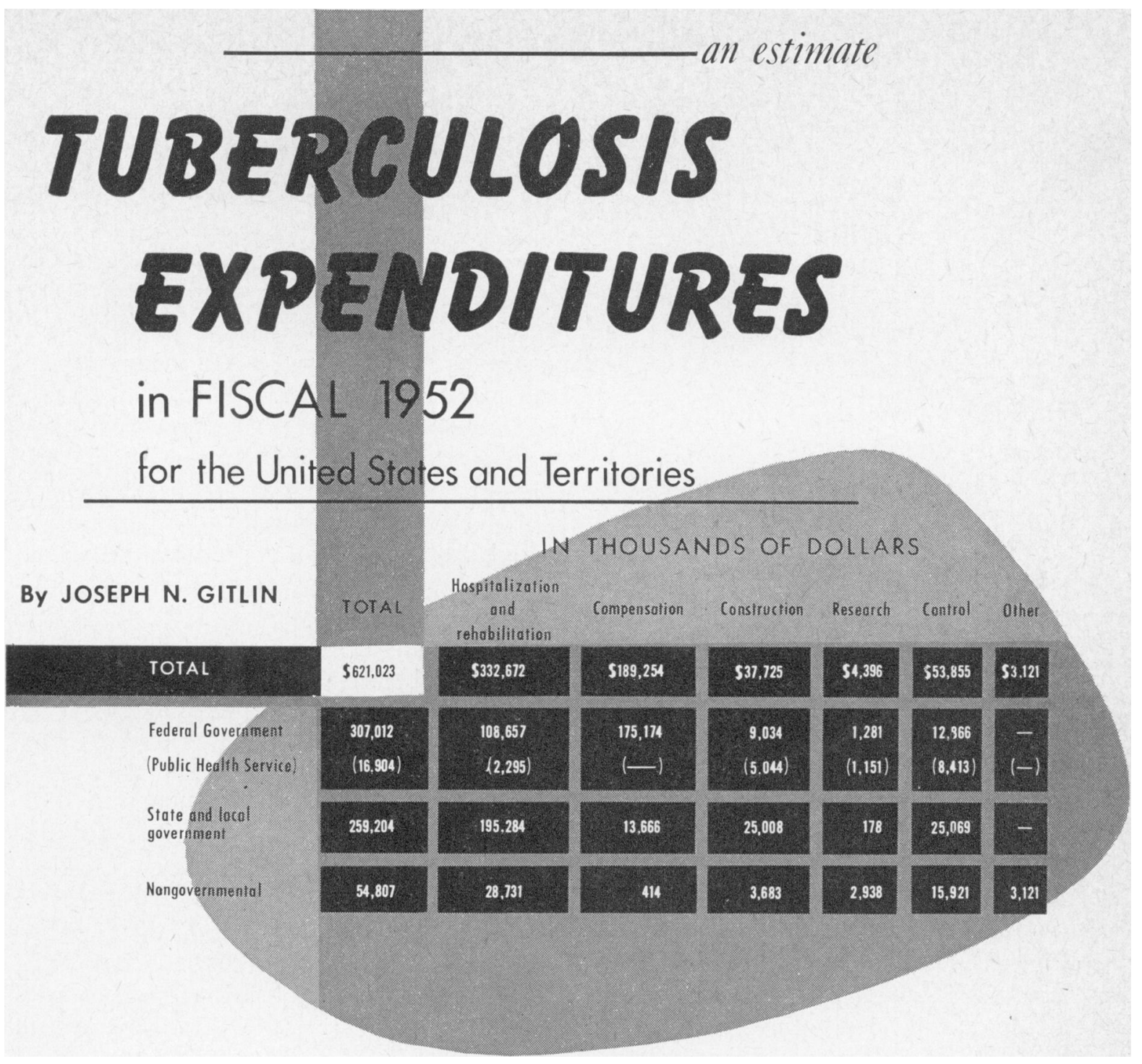

$\mathrm{F}_{\text {the total cost of any disease causing death }}^{\text {ROM }}$ and disability may be divided into the following three general areas:

Cash outlays during a given period for all items attributable to the disease.

Mr. Gitlin, a health program adviser since July 1951 with the Chronic Disease and Tuberculosis Program, Division of Special Health Services, Public Health Service, is on temporary duty with the Air Force. He is presently assigned to the Air University, Gunter Air Force Base, Montgomery, Ala.
Loss of income-or its precursor and corollary, loss of production-during a given period, resulting from illness or from disability caused by the disease.

Loss of potential future earnings during a given period because of death from the disease before the expected age of retirement.

This report-a result of a Public Health Service study initiated with the hope of arriving at the total cost of tuberculosis in the United States and its Territories-is concerned only with the first of the three general areas listed above: cash outlays during a given period for all items attributable to the disease for which data are available. 
These estimates of tuberculosis expenditures are based on reports submitted to the Public Health Service by other Federal agencies and by State and local governments; and on reports from the National Tuberculosis Association and on a variety of other available material. In order to conform to the reporting system followed by most of the agencies submitting reports, the Federal fiscal year 1952 rather than the calendar year 1952 has been used as the time period for which expenditures are shown.

\section{Results of the Study}

During the 12 months beginning July 1, 1951, and ending June 30, 1952, it is estimated that the following amounts were spent in the United States and its Territories as a result of tuberculosis and to prevent or control the effect of the disease :

Federal Government- $\$ 30 \tau$ million, of which $\$ 1 \%$ million was administered by the Public Health Service.

State and local governments-\$259 million.

Nongovernmental agencies-\$55 million.

The resulting total of $\$ 621$ million is believed to represent a very conservative estimate of actual expenditures for tuberculosis. This is so partly because of the exclusion of tuberculosis expenditures in State and local mental and penal institutions, but primarily because of the exclusion of expenditures by individuals with tuberculosis for medical care by private physicians outside hospitals and sanatoriums. In terms of magnitude, this second item could be the most important exclusion with respect to cash outlays. Not to be overlooked, too, as a sizable item of exclusion, is the cost of administration. Although the costs of administration were included in the figures reported for some of the programs, such as those of the States, for the most part it can be assumed that these figures have been generally excluded except where specifically indicated.

In the accompanying tabulation, reports from the following Federal agencies were incorporated under the subcategory "Federal Government": the Departments of Agriculture, the Army, the Navy, and State (United States Foreign Service); the Public Health Service and the Veterans Administration; the Bureaus of Employees' Compensation, Indian Affairs, Prisons, and Public Assistance; the Office of Vocational Rehabilitation; and Freedman's Hospital and St. Elizabeths Hospital-both Federal hospitals.

Included under the subcategory "State and local government" is the expenditure of nonFederal public funds by such agencies as health departments, State boards of control, special tuberculosis commissions, welfare departments, and public hospitals which are independent of other agencies.

The nongovernmental subcategory includes, among others, the following agencies reporting-or reported to have-expenditures attributable to tuberculosis: the National Tuberculosis Association and its affiliates throughout the country, nongovernmental hospitals, private foundations, universities and colleges, and manufacturing firms.

In the tabulation, addends may not sum to totals because of rounding. Definitions of the categorical terms used and a discussion of the data included and excluded from the specific categories and subcategories follow.

\section{Hospitalization and Rehabilitation}

Under the heading "Hospitalization and Rehabilitation" are included estimated expenditures for $(a)$ hospital care of persons with tuberculosis, $(b)$ services provided for persons with tuberculosis by outpatient departments of hospitals, and (c) rehabilitation of tuberculosis patients. In this category, rehabilitation of tuberculosis patients has been combined with tuberculosis hospitalization because many of the reports submitted did not show tuberculosis rehabilitation separately. This is probably owing to the fact that in recent years it has been the policy of many hospitals to institute tuberculosis rehabilitation as an integral part of the tuberculosis patient care. The total figure includes about $\$ 6$ million specifically identified as expenditures for rehabilitation.

The Federal Government portion of this category comprises estimated expenditures, as reported by 11 Federal agencies, for $(a)$ tuberculosis hospitalization, (b) tuberculosis outpatient service, and $(c)$ tuberculosis rehabili- 
iation. The figure is composed largely of hospital care of tuberculosis patients in Federal institutions. However, it also includes payments made by Federal agencies to non-Federal iospitals and sanatoriums for the care of Fedral beneficiaries with tuberculosis. Of the Federal Government total, approximately $\$ 2.3$ inillion was administered by the Public Health service.

The State and local government portion of this category is based primarily on the number of tuberculosis beds occupied in State and local government hospitals and sanatoriums as of January 1, 1952, and the average cost per patient-day for non-Federal Government tuberculosis hospitals.

The number of beds occupied was obtained from questionnaire returns in an annual Public Health Service survey of tuberculosis beds in hospitals and sanatoriums.

The cost per patient-day was obtained from data on 1952 national hospital finances published in the administrative guide section, part 2 of the June 1953 issue of Hospitals (vol. 27, table 5, p. 24), the journal of the American Hospital Association.

The State portion of this estimate has been substantiated by data collected for another purpose by the Public Health Service. (Reference is made to the study, "Distribution of Health Services in the Structure of State Government, 1950," by Aaron W. Christensen, Evelyn Flook, and Georgia B. Druzina-Public Health Service Publication No. 184, part 3, table 5, p. 144). The States' share of the cost of financing vocational rehabilitation for the tuberculous is also included here.

The nongovernmental figure is based primarily on the number of tuberculosis beds occupied in nongovernmental hospitals and sanatoriums as of January 1, 1952, and the average cost per patient-day in nongovernmental tuberculosis hospitals. The data used are from the same sources for State and local government figures noted in the preceding section. Also included are nongovernmental tuberculosis rehabilitation expenditures for which data were available.

Primarily because of the exclusion of expenditures attributable to tuberculosis in State and local mental and penal institutions, the total for the category "Hospitalization and Rehabilitation" is probably an underestimate, as previously noted. The figure 25,000 is the most recent (1952) and authoritative estimate of the number of persons hospitalized with tuberculosis in State and local mental and penal institutions in the United States and Territories. No data are available showing the increment in the costs of caring for these people because they have tuberculosis.

Expenditures by some foundations for the rehabilitation of tuberculosis patients have also been excluded because the data were not available.

Since there is a great deal of reimbursement of funds among various agencies for tuberculosis hospital care, it was necessary to adjust several of the reported figures. Most of these adjustments resulted merely in the transfer of amounts from one subcategory to another. For example: The amount for tuberculosis hospitalization reported by Freedmen's Hospital, a Federal agency under the Department of Health, Education, and Welfare, included reimbursements made to Freedmen's Hospital by the District of Columbia. The amount of reimbursement was added to the State and local total and subtracted from the Federal total. Similarly, payments to municipal hospitals for tuberculosis hospitalization reported by the Veterans Administration were subtracted from the State and local total in order to avoid duplication.

\section{Compensation}

The "Compensation" category includes reported payments to individuals or to their relatives or dependents because of death or disability caused by tuberculosis. Mlso included is $\$ 750,000$ which was paid by governmental agencies to farmers for the destruction of tuberculous livestock, even though the argument has been advanced that payments to farmers for the destruction of tuberculous livestock are made to enlist their cooperation in tuberculin testing programs designed to prevent the spread of tuberculosis to humans, and that for this reason these payments should be considered as control expenditures. While the inclusion of such payments here is admittedly 
arbitrary, it is felt that for the purposes of this study they more nearly conform to the definition of compensation than to the definition of control.

The question of including under this category insurance payments resulting from death or disability as a result of tuberculosis has been considered. In the instance of death benefits paid on insured individuals, it was strongly felt that, because of the prepayments by the individuals themselves, the funds were not directly attributable to tuberculosis as a cost because they are analogous to a "savings plan." In the instance of health and accident insurance programs, it was found that generally a long-term illness such as tuberculosis is specifically excluded from health and accident policies as a compensable condition.

The Federal Government portion of this category consists largely of payments made by the Veterans Administration to veterans disabled because of tuberculosis and to dependents of veterans who have died of tuberculosis. Also included here are payments because of tuberculosis under the Social Security Administration's Bureau of Public Assistance programs of "aid to dependent children" and "aid to the permanently and totally disabled," and payments made because of tuberculosis by the Bureau of Employees' Compensation in the Department of Labor, and Federal moneys used to compensate farmers for the destruction of tuberculous livestock.

The State and local government portion of this category is composed of estimated amounts attributable to tuberculosis contributed by State and local governments in the State programs termed "aid to dependent children," "aid to the totally and permanently disabled," and "general assistance," and as compensation to farmers for the destruction of tuberculous livestock. Amounts paid to individuals under State temporary disability programs have not been included because they are in principle comparable to insurance plans.

The nongovernmental amount reflects the total of amounts reported by nongovernmental agencies spent primarily for emergency relief to individuals because of tuberculosis.

The $\$ 189,254,000$ total for "Compensation" is probably somewhat underestimated because of the exclusion of payments made as compensation for tuberculosis by the Bureau of Indian Affairs in the Department of the Interior, and by the Children's Bureau in the Social Security Administration. Although both bureaus recognize that substantial compensatory payments are made as a result of tuberculosis, no basis could be found upon which to estimate accurately that part of the total compensatory payments specifically attributable to tuberculosis.

The inclusion of amounts paid to workers from workmen's compensation plans, which are generally employer-supported programs, has also been considered for this category, but when it was found that the number of cases of tuberculosis resulting from occupational conditions was insignificant, compared to the total number of persons disabled by tuberculosis, the amount of these compensatory payments was omitted.

\section{Construction}

The category headed "Construction" includes the estimated value, during the fiscal year 1952 , of hospital construction which was intended to facilitate the care and treatment of persons with tuberculosis. Although this includes, for the most part, the building of tuberculosis hospital beds, it also includes additions to, and improvements in, existing tuberculosis facilities. The purchase of hospital equipment used primarily for the care and treatment of persons with tuberculosis is also included.

The Federal Government portion of the total comprises estimates of the amounts expended by reporting Federal agencies for the construction of tuberculosis hospital facilities, including $\$ 5$ million administered by the Public Health Service under the Hill-Burton program (Hospital Survey and Construction Act, Public Law 725, 79th Cong., 2d sess.).

The State and local government portion represents the estimated value of tuberculosis hospital construction by State and local governments including the estimated State and local share contributed to the Hill-Burton program.

The nongovernmental portion of the total is the estimated value of tuberculosis hospital construction by nongovernmental agencies including the nongovernmental share contributed to the Hill-Burton program. 
Construction estimates are based primarily on a table prepared by the Public Health Service, showing the value in current (1952) prices of hospital construction in 1952, and on a table showing the distribution of non-Federal hospital construction during 1950 by type of facility; this table appears in the article entitled, "Hospital Construction Trends" by Louis S. Reed in Modern Hospital, March 1952 (vol. 7, pp. 72-76, table 5). The precision of the estimates is dependent, therefore, on the applicability of the 1950 distribution to 1952. Data available indicate that there had been no appreciable change in the percentage representing the value of non-Federal tuberculosis hospital construction compared with the value of total nonFederal hospital construction. In view of the fact that the number of new tuberculosis beds constructed has been decreasing in relation to total beds constructed, it is probable that there has been an increase in expenditures for the construction of additions to, and the making of improvements in, existing tuberculosis facilities and the purchase of new tuberculosis hospital equipment.

\section{Amounts for Research}

The "Research" category includes all reported expenditures for tuberculosis research, covering such basic or fundamental research as scientific analysis, exploration, and experimentation. It also includes applied research, an example of which is the cooperative applied tuberculosis research engaged in by the Public Health Service. Not included here are expenditures on operational research, which is pertinent to the development and analysis of tuberculosis control programs. This type of research conforms more closely to the meaning of "Control," and such expenditures have, therefore, been included under that heading.

The Federal Government subcategory comprises estimated expenditures reported by Federal agencies engaged in, or supporting, tuberculosis research, including Public Health Service expenditures for both direct research and for grants to universities and for research grants, fellowships, and traineeships to individuals who perform much of the basic tuberculosis research in the United States.
The State and local government expenditure is the total of amounts specifically identified by State, county, and municipal health departments as having been spent on tuberculosis research.

The nongovernmental expenditure is the total of amounts reported as having been spent on tuberculosis research by manufacturing firms, foundations, voluntary health agencies, and universities.

Both the State and local government and nongovernmental subtotals were obtained from an article by Virginia Cameron entitled "The Cost of Research in Tuberculosis in the United States," published in The American Review of Tuberculosis (vol. 60, pp. 393-405, October 1949). In this report, considered to be the most recent and authoritative on the cost of tuberculosis research, Cameron analyzes allocations for tuberculosis research in 1947-48. This analysis has been used as a basis for the estimates of 1952 expenditures since, in recent years, the level of tuberculosis research by State and local health departments and nongovernmental agencies has been largely influenced by the investigation of chemotherapeutic agents. In this connection, it is believed that the investigation of isoniazid in 1952 exerted about the same influence on tuberculosis research as the investigation of streptomycin did in 1947-48.

It is recognized that a considerable amount of tuberculosis research is conducted in hospitals and sanatoriums-especially State and local-the cost of which is usually absorbed in the total cost of hospitalization without being specifically identified. For this reason, the total for "Research" is probably somewhat understated, while the total for "Hospitalization and Rehabilitation" is correspondingly overstated by an unknown amount.

\section{The "Control" Column}

Included under "Control" are estimated expenditures attributable to tuberculosis for the provision of such services as case finding, diagnostic and treatment clinics, public health nursing facilities, laboratory facilities, operational research studies, health education, training programs, case register systems, and administration. 
The Federal Government subtotal comprises estimated amounts spent for control by reporting Federal agencies, including the Departments of Agriculture, the Army, and the Navy; the Veterans Administration, and the Bureau of Indian Affairs of the Department of the Interior. It also includes about $\$ 8.4$ million administered by the Public Health Service, of which grants to the States is the largest single item.

The State and local government amount is the sum of specific allocations for control reported by State and local government agencies plus the estimated portion of State and local government allocations for general health services that were used for tuberculosis control. Reported State and local expenditures for the administration of bovine and avian tuberculosis control have also been included.

The nongovernmental figure is the total of amounts reported by voluntary health agencies for such items as case finding, health education, program development, maintenance of clinical and nursing facilities, and administration. This subtotal is considerably underestimated because of a lack of data on which to base an estimate of tuberculosis control expenditures by universities, other schools, and manufacturing firms.

The amount of understatement in the "Control" total is increased by the exclusion of amounts spent for education in tuberculosis in medical and nursing schools, for X-ray technician courses, and for other academic training received by persons engaged in the field of health. It was not possible to estimate an amount covering these expenditures because of a lack of available data on this subject.

\section{The "Other" Category}

The category called "Other" comprises amounts reported by nongovernmental agencies for such items as business management, tuberculosis fund-raising activities, as well as amounts included under the category of "Miscellaneous" in their reports to the Public Health Service.

Two additional areas of expenditures might theoretically have been included here as attributable to tuberculosis. They are the cost of supplying various types of insurance involving tuberculosis and the cost of collecting taxes which are used in part for tuberculosis control. Neither of these areas was included because of a lack of data concerning the distribution of total costs over the many diseases invloved, the services provided, and the functions served. It has been argued that a part of such costs cannot validly be attributed to tuberculosis since, if tuberculosis were eliminated, the cost of providing insurance and of collecting taxes would not be affected.

\section{Legal Note on Fluoridation Cases}

The supreme courts of two States-Louisiana and Oklahoma-have recently upheld programs for the fluoridation of municipal water supplies as valid exercises of the police power and involving no unconstitutional invasion of personal liberty-Chapman v. City of Shreveport, Shreveport Times, June 3, 1954 (La. Sup. Ct. May 31, $1954)$; Dowell v. City of Tulsa, 23 U.S. L. Week 2007, XXV OKLA. BAR J. 116 (Sup. Ct. June 15, 1954).

The United States Supreme Court in June 1954 denied review (347 U.S. 1012, 74 S. Ct. 863) in the California fluoridation case, De Aryan v. Butler, 119 Cal. App. 2d 674, 260 Pac. 2d 98 (1953). 